\title{
FrameNet, Barsalou Frames and the Case of Associative Anaphora
}

\author{
Alexander Ziem
}

\begin{abstract}
This paper introduces and compares the currently most important approaches to frames: the FrameNet project pursued at the 'International Computer Science Institute' in Berkeley and Barsalou's cognitive frame theory supplemented by Löbner's concept type theory. On the basis of empirical findings of a case study on associative anaphora, it is argued that both approaches complement each other in several respects. While, for example, Barsalou's theory concentrates on sortal concepts, disregarding semantic and syntactic valences of each word in each of its senses, FrameNet focuses on relational concepts, particularly verbs and deverbal nouns. In contrast to frames as described in terms of valency patterns within FrameNet, linguistic approaches drawing on Barsalou's theory emphasize that frames are embedded structures having a rich internal structure. By comparison, serious shortcomings and drawbacks of each approach become apparent.
\end{abstract}

\section{Introduction}

The notion frame goes back to Minsky's influential paper on knowledge representation (Minsky, 1975), and since then it has been a central, but also ambiguous and controversial, concept in many disciplines (for an overview cf. Ziem, 2008, pp. 13-35), including cognitive semantics (e. g., Fillmore, 1976, 1977, 1985, 2006), computational linguistics (Petersen, 2007/2015, among others), artificial intelligence (e.g., Charniak, 1976; Hayes, 1980), cognitive psychology (e. g., Schank \& Abelson, 1977; Barsalou, 1992), and Media Sciences (Scheufele, 2003; Matthes, 2007). In spite of the vivid discussions in the 1980s, in current research the frame concept seems to have become less attractive. However, there are two exceptions. On the one hand, Fillmore's early account of semantic frames has been put 
into practice within FrameNet, a large-scale computational lexicography project hosted at the University of Berkeley, California (for an overview cf. Boas, 2005; Fillmore, Johnson \& Petruck, 2003). Similarly, also Barsalou's frame theory has recently been readdressed and further developed, namely in the research projects "Frames and functional concepts" (FOR 600) and "The Structure of Representations in Language, Cognition, and Science" (SFB 991), both hosted at the University of Düsseldorf.

The starting point of the present paper is the fact that both approaches seem to be based on a mutually shared definition of frames. While FrameNet sees frames as a "script-like conceptual structure that describes a particular type of situation, object or event, along with its participants and props" (Ruppenhofer et al., 2010, p. 5), Barsalou (1992, p. 21) proposes that "frames are dynamic structures whose form is flexible and context-dependent". However, significant differences relate to the theoretical prerequisites of each approach. Barsalou's frame model is cognitive in nature; it addresses frames as mental entities. FrameNet, on the other hand, is first and foremost a linguistic approach to lexical meaning grounded in the concept of semantic and syntactic valency. As a result, both approaches differ substantially in the way their methodology is put into practice.

Taking so-called associative anaphora (henceforth: AA) as a 'test case', this paper aims at providing a theoretical and methodological comparison of the two currently most sophisticated approaches to frames. An associative anaphor establishes indirect reference to a previously introduced discourse referent (e. g., $k e y \rightarrow$ car, cf. Ex. 1). Focusing on the resolution of indirect text reference, the present paper addresses the following kinds of issues, among others: How does FrameNet and a Barsalou-inspired approach to frames account for reference resolution in the case of AA? Do both approaches adequately describe and explain the phenomenon addressed? And most importantly: Given the results of the case study, what are the assets and drawbacks of each approach? Is it possible to (partly) integrate both approaches in one another, yielding a more comprehensive frame theory?

The paper is structured as follows. In Section 2, I will briefly introduce the most important properties of associative anaphora. This section also provides a preliminary typology of AAs, including definite associative anaphors with either verbal or nominal antecedents as its most important subclasses. Section 3 sketches out Barsalou's approach to frames and its extensions yielded in the re- 
search project FOR 600 insofar as it is relevant for applications to DAAs. Likewise, Section 4 introduces the methodology offered by FrameNet in order to investigate DAAs. Finally, Section 5 summarizes and compares the results. Based on these findings, it draws some conclusions pointing to promising perspectives for future frame-semantic research.

\section{The case of associative anaphora}

Following the standard definition, an AA, sometimes also called "bridging anaphor" (Clark, 1975) or subsumed under "indirect anaphor" (Schwarz, 2000) is a first-mentioned use of a definite or indefinite expression that establishes indirect reference to a previously introduced discourse referent in a text (Löbner, 1998). In (1), for example, the reader mentally creates a concept for the anaphoric NP the key that includes information about the previously introduced discourse referent car, yielding the more complex concept "Peter's car key". The possessor argument of key is saturated with conceptual information that the antecedent his car provides.

(1) Peter walked to his car [antecedent]. He had forgotten the key [associative anaphor].

When a referential use of an NP prompts the reader to construe a concept for this entity, the lexical frame is subsequently enriched by idiosyncratic information either provided by the context or inferred from background knowledge. In the context of (1), for example, the concept associated with key indirectly relates to the NP his car. More specifically, the key is interpreted as the key of Peter's car. Note that associative anaphors have no deictic quality; in order to determine the reference of the noun key, for example, a conceptual representation of the respective referent is construed solely by means of information provided by the discourse referent car and the AA. It is thus the linguistic and not the situational context of the anaphorically used definite NP the key that helps to identify the referent of the NP.

To gain a deeper understanding of forms and functions of AAs in texts, it is useful to distinguish between different types of AAs (for a typology based on so-called "activation types" cf. Schwarz, 2000). First, a frequently found distinguishing criterion relates to definiteness/indefiniteness of AAs. 
(2) They passed an old monastery. A window was smashed.

Indefinite associative anaphors, such as exemplified in (2), are exceptional; the majority of AAs belong to the class of definite associative anaphors (henceforth: DAAs). This class comprises four important subclasses, exemplified in (3)-(6). As the examples (3) and (4) indicate, antecedents of DAAs may be verbal or nominal. Note that the class of DAAs with nominal antecedents comprise not only deverbal nouns, like search in (4), which are inherently relational, but also sortal nouns, like house in (5), which lack this feature (for the distinction of noun types cf. Horn \& Kimm, 2014, also: Löbner, 1998).

(3) Peter bought a new Mercedes. The price was lower than expected.

(4) The search lingers on, but the key remains lost.

(5) They reached Peter's house. The window pane in the door had been smashed.

Another distinguishing criterion concerns the kind of reference to be established between AAs and their antecedents (Greber, 1993; Kleiber, 2001). Associativeanaphoric reference may be direct or indirect. Indirect DAAs are characterized by nominal DAAs whose referents are not indirectly anchored in the concept associated with the antecedent but in a sub- or superordinate concept. In the case of (6), for example, the associative anaphor the menu is not interpreted as the waiter's but as that of the restaurant in which the waiter is serving.

(6) The waiter came to our table. He had forgotten the menu.

In this view, DAAs with verbal antecedents also belong to the class of indirect DAAs since they are indirectly anchored in a concept associated with the antecedent's concept. In (3), for example, the DAA the price is not the price of buying but the purchase price of the product. Table 1 summarizes the subclasses of AAs mentioned so far. In the following I will concentrate on DAAs as the prototype of AAs.

In the case of DAA, it is the definiteness of the NP that triggers a referential interpretation of the NP. Discussing different theories of definiteness, Lyons (1999) distinguishes between (a) the familiarity approach (exemplified in Heim, 1982) which assumes that the definite article exhibits familiarity to both speaker and 
FrameNet, Barsalou Frames and the Case of Associative Anaphora

Table 1: Types of associative anaphora (AA)

\begin{tabular}{|c|c|c|}
\hline Type of AA & Example & Referential properties of $\mathrm{AA}$ \\
\hline $\begin{array}{l}\text { Direct definite associative } \\
\text { anaphora }\end{array}$ & $\begin{array}{l}\text { Peter walked to his car. } \mathrm{He} \\
\text { had forgotten the key. }\end{array}$ & $\begin{array}{l}\text { Relational, unique reference } \\
\text { of nominal antecedent }\end{array}$ \\
\hline $\begin{array}{l}\text { Direct indefinite associative } \\
\text { anaphora }\end{array}$ & $\begin{array}{l}\text { Peter passed the house. A win- } \\
\text { dow was smashed. }\end{array}$ & $\begin{array}{l}\text { Relational, non-unique refer- } \\
\text { ence of nominal antecedent }\end{array}$ \\
\hline $\begin{array}{l}\text { Indirect definite associative } \\
\text { anaphora }\end{array}$ & & \\
\hline $\begin{array}{l}\text { 1. with a nominal } \\
\text { antecedent } \\
\text { 2. } \begin{array}{l}\text { with a verbal } \\
\text { antecedent }\end{array}\end{array}$ & $\begin{array}{l}\text { The waiter came to our table. } \\
\text { He had forgotten the menu. } \\
\text { Marie left Berlin yesterday. } \\
\text { The train was late again. }\end{array}$ & $\begin{array}{l}\text { Relational, unique 'indirect' } \\
\text { reference(transitive verb) }\end{array}$ \\
\hline
\end{tabular}

hearer, and (b) the identifiability approach which hypothesizes that the definite article indicates that the addressee is able to identify the referent on the basis of given information. In either approach, the definite article in (1) gives rise to a referential reading of key in such a way that it is interpreted as Peter's car key. Analogously, in (2) the DAA unambiguously denotes one particular concept that serves as a semantic role of the verbal antecedent. This brief description of DAAs suffices to test and compare in Section 2 FrameNet and Barsalou frames regarding their descriptive adequacy.

Traditional approaches to AA suffer from three shortcomings. However, as I will argue later, a frame theory that incorporates insights from both Barsalou's and FrameNet's approach might be capable of overcoming these deficits. First, traditional approaches fail to explain the 'felicity conditions' required for anaphoric-reference resolution. In his still influential approach, Hawkins (1978, p. 107), for example, hypothesizes that frequent co-occurrences of the anaphoric and antecedent expression license anaphoric reference. The frequency condition, however, is not met in many attested examples of associative anaphors (Löbner, 1998, p. 10). Second, it is not clear how contextually 'enriched' anaphoric meanings emerge. While Heim's formal approach assumes an additional mechanism, namely "accommodation" (Heim, 1982, p. 370), Schwarz (1996) postulates very abstract semantic constraints. Still, it is anything but obvious how these semantic constraints or accommodations may account for instances such as (1)-(6). Finally, a principal problem lies in explicating the relations holding between anaphors and their antecedents. The relations holding between DAAs and their antecedents 
seem to be less restricted than commonly assumed in literature. Within traditional frameworks (e. g., Greber, 1993, pp. 379-387; Kleiber, 2001, pp. 263-296), it seems to be problematic to delimit the number of relations, and it is hard to provide a precise and maximally exhaustive classification without creating a potentially unlimited number of relations. In the next sections, the application of FrameNet and Barsalou frames aims at elucidating both the analytic assets and drawbacks of each approach.

\section{Investigating associative anaphora with Barsalou frames}

\subsection{Frames as recursive attribute-value-structures: Barsalou's approach and its extensions in FOR 600}

In several papers the cognitive psychologist Lawrence W. Barsalou has outlined a cognitive frame theory that tries to take account of empirical findings in the field of cognitive and experimental psychology (Barsalou, 1992, 1993; Barsalou \& Hale, 1993). In contrast to FrameNet, Barsalou's approach is designed as a genuinely cognitive theory aiming at a comprehensive account of human knowledge representation. Thus, Barsalou's primary objective is not to develop a semantic theory but a psychologically realistic theory of knowledge representation, including semantic representations as one component. Accordingly, Barsalou (1992, p. 21) postulates that frames, defined as recursive attribute value-structures, provide "the fundamental representation of knowledge in human cognition". He presents arguments why his frame theory is explanatorily more adequate than traditional feature list representations of categories. In terms of the application scope of frames, however, it is striking that the great majority of instances discussed in Barsalou (1992) (e.g., car, vacation, bird, mare, animal) are limited to nominal sortal concepts.

Barsalou's frame theory has been adapted, extended, and slightly modified within a linguistic framework. Based on ideas developed in Löbner (1998) and other papers addressing a theory of concept types (cf. Löbner 2011 for an overview), the research unit "Frames and Functional Concepts" (FOR 600) as well as the research project "The Structure of Representations in Language, Cognition, and Science" (SFB 991) aim at developing a semantic theory allowing for deep lexical-semantic decomposition within a formal-logical framework. As a first step, a formal theory of frames based on Barsalou frames was developed (Pe- 
tersen, 2007/2015). Major advances concern the integration of nominal concept types, including their interaction with determination. More specifically, Löbner's concept theory and Barsalou frame approach were integrated into one another in such a way that frame attributes (in Barsalou's sense) are essentially equated with functional concepts. Hence, it is assumed that attributes are characterized by two constitutive features: relationality and uniqueness of reference. Assuming that each attribute denotes precisely one entity of the respective frame allows for mathematical modeling and formalizations of frames. As we will see in the following paragraph, this assumption is also highly relevant for explaining the resolution of AAs.

\subsection{Putting Barsalou frames into practice: DAAs with nominal antecedents}

In Section 2, it has become evident that a distinguishing feature of DAAs is uniqueness of reference. That is, a DAA is always interpreted in such a way that it unambiguously refers to precisely one entity which has indirectly been introduced into the discourse. To come straight to the point: It is one of the major merits of Barsalou's approach to DAAs (extended by Löbner's concept type theory) to provide a comprehensive explanation of this property of DAAs.

It is argued that a DAA refers to the (value of an) attribute in the frame of the antecedent in such a way that the DAA is construed as a functional concept. More specifically, Löbner (1998) argues that definite associative anaphors equate with functional concepts for which a possessor and a situational argument are specified in context. And since functional concepts are equated with frame attributes, a DAA is interpreted as an attribute of the frame evoked by its antecedent. To illustrate, consider again (1) where the definite article gives rise to a referential reading of key in such a way that it is interpreted as the key for Peter's car.

(1) Peter walked to his car [antecedent]. He had forgotten the key [associative anaphor].

For instances such as (1) it is characteristic that the built-up concept is functional because it meets the conditions of relationality and uniqueness of reference (for an overview of concept types and their properties see Löbner 2011; cf. also Horn $\&$ Kimm, 2014). Its indirect reference is unique in that the number of possible ref- 
erents is restricted to only one indirect referent, namely Peter's car. The observation that DAAs correspond to attributes in the frame of the antecedent's referent provides an opportunity to gain insights in the composition of these frames. To the extent that the respective attribute can be considered a necessary component of the antecedent frame, one obtains information about meaning components of the antecedent nouns.

According to this theory, the head noun of a definite associative-anaphoric NP undergoes a type shift if its underlying lexical concept is not functional (for critical discussions of type shifts cf. Horn \& Kimm, 2014). In example (1) a type shift is not necessary since the underlying lexical concept of key is already functional: there is prototypically one and only one key that belongs to a car. Compare, however, example (7), where window - the head noun of the associative-anaphoric $\mathrm{NP}$ - is not functional but relational on the lexical level.

They reached Peter's house. The window pane in the door had been smashed.

The underlying lexical concept of window is relational (and not functional) because a house usually has more than one window. The possible referents of window is thus not restricted to only one referent. In order to facilitate uniqueness of reference, window is the object of a shift from a relational to a functional concept with a possessor argument specified by the antecedent. Such conceptual shifts are always necessary if the head noun of an NP surfacing as a DAA is non-functional on the lexical level; only functional concepts allow for unique reference.

Moreover, a frame-theoretical account of DAAs based on Barsalou's frame conception and Löbner's concept type theory correctly predicts the type of relation holding between anaphors and antecedents, and it also provides substantial suggestions how discourse referents in a text may be represented as Barsalou frames. Since it is assumed that the DAA has a functional head by default, every possible type of attribute in a frame representing the referent of the antecedent NP is also a possible type of DAA. The types usually enumerated in literature, such as parts, roles, contiguity relations, etc. (cf. Greber, 1993; Kleiber, 2001; Schwarz, 2000, among others), are all subsumed under this methodology. This approach thus abandons any thematic restrictions on DAAs and their underlying relation, without having to rely on empirical corpus evidence, since the argument presented 
here is theoretical in nature. On the other hand, the approach is more restrictive than traditional approaches in observing that the relation between the referent of the antecedent and the DAA referent must in fact be a functional one (cf. Löbner, 1998, 2011).

According to Barsalou (1992), recursivity constitutes an essential property of frames. The principle of recursivity also holds for a DAA in that it may be the possessor of another DAA, thereby forming a chain that represents relations between discourse referents in a network structure (for details cf. Ziem, 2012). Hypothesizing that DAA referents themselves are also represented in frames, the theory models DAAs as direct conjunctions of antecedent frames and DAA frames. If a DAA is the possessor of another DAA, frames are recursively linked to each other, constituting a complex frame network of newly introduced discourse referents. This is the case in (8).

(8) It was late when John arrived at his brother's house. The door was closed. Last week, John had lost the key, but fortunately he had received a substitute straight away.

In (8), door is interpreted as the door of the house mentioned before, while key is conceptualized as the key for this door. Once associative-anaphoric references are resolved, the construed concepts are 'enriched' by context information, yielding the complex concepts "the door of John's brother's house" respectively "the key for the door of John's brother's house". Modeling such chains of DAAs in frame networks could ultimately lead to a representation of correlated discourse referents in one single frame.

To conclude, Barsalou's frame theory supplemented with Löbner's concept type theory takes account of at least three basic properties of DAAs. By equating a DAA with a functional concept surfacing as an attribute of the frame evoked by the antecedent, the approach first successfully explains the difference between definite and indefinite associative anaphors: the reference of DAAs, but not the reference of IAAs, is unique in that it is directed to precisely one entity indirectly introduced into the discourse world before. Second, it correctly predicts the relations holding between a DAA and its antecedent(s). Instead of postulating an arbitrary number of relation types, it is hypothesized that the number of DAAs (attributes) associated with a frame is potentially unlimited. Finally, recursiv- 
ity, as a constitutive property of Barsalou frames, allows explanation of chained associative-anaphoric references, that is, NPs serving as DAAs and antecedents (for other DAAs) at the same time. However, a major shortcoming concerns the limitation of the approach to DAAs with nominal antecedents. It is anything but clear whether the approach can be successfully applied to DAAs with verbal antecedents, simply because both Löbner's concept type theory and Barsalou's frame theory are restricted to nominal frames. Currently, however, Robert Van Valin and Rainer Osswald are developing a theory of verb meaning based on Barsalou frames. In the long run, this theory might help to extend the application scope of Barsalou frames in the realm of AAs.

\section{Investigating associative anaphora within FrameNet}

\subsection{Frames as valency pattern: background to FrameNet}

Frames, as defined in FrameNet and Fillmore's early seminal studies on semantic frames (e.g., Fillmore, 1976, 1977, 1985), are rich conceptual knowledge structures underlying and motivating the meaning(s) of lexical items and phrasal units. Building on this definition, the FrameNet project pursued at the International Institute of Computer Science in Berkeley tries to develop an online lexical database for English documenting the semantic and syntactic valences of a word in each of its senses (Ruppenhofer et al., 2010, p. 5). It has been, and still is, one of the major aims of FrameNet to put Fillmore's early theoretical ideas about semantic frames into practice by developing an annotation tool that allows for datadriven, rather than introspective, lexical-semantic investigations. At the end, the database is supposed to provide all semantic information required for adequately understanding lexical and phrasal units in context (Fillmore, Wooters \& Baker, 2001).

In FrameNet, the target units are so-called lexical units, that is, word-meaning pairings. The starting point is the assumption that each word (in each of its senses) evokes a frame providing a set of "frame elements" (FEs); each sense of a polysemous word thus belongs to a different frame (Ruppenhofer et al., 2010, p. 5). FEs are equated with semantic and/or syntactic roles that a lexical unit takes. A distinction is made between peripheral and core FEs - a distinction that seems to be analogous to the argument-adjunct differentiation in valency grammar. Unlike valency grammar, however, FEs are not limited in number since 
they are identified - and subsequently defined - "bottom-up", that is, on the basis of annotated sentences. It is hypothesized that frames are not isolated entities in the language user's mind. Rather, they are linked by a system of frame-to-framerelations with one another. Fillmore \& Baker (2010, p. 330) list seven relations falling into three groups: (a) generalization relations ("inheritance", "perspective", "using"), (b) event structure relations ("subframes", "precedes"), and (c) systematic relations ("causative of", "inchoative of"). I will come back to them later when analyzing instances of DAAs.

Due to the valency-oriented view on word meaning, FrameNet primarily focuses on frames associated with verbs, relational nouns, and adjectives. Presently, about 7,700 lexical units have been annotated on the basis of approximately 173,000 sentences. About 3,260 verb senses, 2,940 noun senses, and 1,440 adjective senses have been identified. The exemplary investigations of associative anaphora in the next paragraph will build on these data, particularly on the (sub-)frames fully annotated so far. Note, as mentioned before, that the methodology offered by FrameNet only allows for detailed investigations of those associative anaphors whose antecedents surface as verbs or relational nouns; in contrast to Barsalou's approach to frames, FrameNet does not focus on sortal nouns as frame-evoking elements even though they are also addressed and covered in the database.

\subsection{Putting FrameNet frames into practice: DAAs with verbs and deverbal nouns as antecedents}

Although FrameNet's main focus is on frame-semantic investigations of lexical units within the limits of the sentences they are embedded in, in a couple of papers and books it has been argued persuasively that frames play also a crucial role in the domain of text semantics. Fillmore (1984), for example, takes the view that text semantics, on a par with lexical semantics, constitute the most prominent level of semantic investigations. In line with this view, Fillmore \& Baker (2001) illustrate that 16 frames provide semantic prerequisites for the understanding of a small story about a criminal process. Thus, it is principally possible to apply the FrameNet methodology to textual phenomena such as AAs.

How does a FrameNet approach to AA proceed? To begin with, consider (9) where the referent of the definite noun phrase (NP) the car refers indirectly to the concept of driving introduced before. 
(9) We drove [antecedent] to Frankfurt yesterday. The car [associative anaphor], however, was a bit too small.

In FrameNet terms, drive evokes in (9) the Operate_vehicle frame providing VEHICLE as one of its core elements. By virtue of frame-to-frame relations, the Operate_vehicle frame imposes a particular perspective on the related Use_vehicle frame. Hence, the associative anaphor the car specifies one particular FE of the frame evoked by the antecedent. In (9) associative anaphoric reference succeeds because VEHICLE is not overtly realized in the first sentence. Given the local context provided in (9), the so-called "definite null instantiation" (cf. Ruppenhofer et al., 2010, p. 24) of the FE VEHICLE is instantly accessible.

More generally, one can conclude that a FrameNet approach to associative anaphora supports the assumption that an associative anaphor is anchored in the frame evoked by the antecedent in such a way that it conceptually specifies one of the FEs provided by the antecedent frame. This also holds for cases such as (4) mentioned above:

(4) The search lingers on, but the key remains lost.

Unlike (9), the antecedent the search is a deverbal noun. However, both the deverbal noun the search as well as the verb search evoke the Scrutiny frame. Thus, the frame associated with the verb and the deverbal noun provides the same FEs, among them the core FE PHENOMENON (that is, in traditional case grammar terms, the semantic role "object"). In (4) it is precisely this FE that is further specified by the associative anaphor the key.

As mentioned above, beyond verbs and deverbal nouns also sortal nouns surface as AAs. For example, in (7) pane is interpreted as a specification of the FE DESCRIPTOR inherent in the Buildings frame evoked by house. Sortal nouns like house challenge the FrameNet approach in numerous respects, since such nouns are characterized as words that "typically serve as dependents rather than clearly evoking their own frame" (Ruppenhofer et al., 2010, p. 5). Although artifact and natural kind nouns have "a minimal frame structure on their own", it is nonetheless hard to see how analyses within a FrameNet approach can fully take account of this subclass of AAs.

Note that FrameNet does not systematically differentiate between different types of concepts. Unlike the approach to associative anaphora introduced in 
Section 3, relational, functional, sortal, and individual concepts are distinguished from one another only in terms of their varying valency pattern. As a result, a FrameNet approach to associative anaphora is not able to support the strong hypothesis that definite associative anaphors and functional concepts share the constitutive properties of relationality and uniqueness of reference. I consider this a methodological drawback, since the property of functionality correctly predicts uniqueness of anaphoric reference in the case of definite associative anaphors. In (4), for instance, the referent of the key is identified with the entity being searched for.

As mentioned above, FrameNet cannot account for associative anaphors whose antecedents surface as sortal nouns since they lack valency. It is worthwhile noting, however, that this does not apply to all cases. Even though in (10), for example, soup is a sortal noun, FrameNet does provide an explanation for the associative-anaphoric reference triggered by spoon.

(10) When the waiter served the soup, he noticed that he had forgotten the spoon.

In contrast to prototypical instances of DAAs with sortal nouns as antecedents, as evidenced in (1), (2), and (5), a distinguishing feature of (10) is that the anaphor and its antecedent are mediated by the inferred Ingestion frame, in which the soup concept specifies the FE INGESTIBLES while the spoon concept specifies the FE Instrument. In (10) it becomes apparent why it is useful to distinguish between frame invocation and evocation (Ruppenhofer et al., 2010, p. 15 f.) - a distinction that is missing in Barsalou's approach. The associative anaphor spoon is related to its antecedent soup by the invoked Ingestion frame. In the case of frame invocation, a FrameNet approach to associative anaphora correctly predicts that both anaphor and antecedent specify FEs (here: INGESTIBLES, INSTRUMENT) of the invoked frame.

While, however, instances such as (10) constitute a sub-class of definite DAAs with antecedents surfacing as sortal nouns, other DAAs with sortal nouns as antecendents cannot be explained within the framework provided by FrameNet. Yet, in turn, FrameNet allows for concise analyses of definite associative anaphors with verbs and deverbal nouns as antecedents. As shown above, these classes of DAAs cause serious problems for Barsalou's approach to frames. 
Can a FrameNet approach to associative anaphora account for recursive anaphor-antecedent structures? Although neither Fillmore himself nor his collaborators seem to consider recursivity a property of semantic frames, there is no fundamental caveat to integrating recursivity into frame-semantic investigations of associative anaphors. Like in (11), an associative anaphor (the car) may be followed by a subsequent sub-associative anaphor (the owner) thereby forming a chain of indirect textual references that expresses relations between discourse referents in a network structure.

(11) Today, Peter drove back home. He borrowed the car from a friend. The owner, however, was Fred.

The NP the car is embedded in a recursive frame structure in such a way that it specifies the FE VEHICLE of the operate_vehicle frame evoked by drive, and at the same time it evokes the Vehicle frame whose FE Possessor is specified by the associative anaphor owner.

\section{Conclusions}

To sum up, Barsalou's approach to frames differs from FrameNet in a number of respects. Most importantly, Barsalou envisages a cognitive theory of knowledge representation in which frames are addressed as a universal mental representation format. Moreover, Barsalou's theory is based on empirical evidence in the field of cognitive psychology. On these grounds, Barsalou defines frames as recursive attribute-value structures. FrameNet, on the other hand, is a genuine linguistic project in that it is both grounded in an extended model of semantic as well as syntactic valency and realized as a large-scale corpus project. Accordingly, frames are not - at least not first and foremost - defined in cognitive terms but in accordance with the annotation categories: on the basis of annotated data FEs and frame-to-frame-relations are identified, and on the basis of these data core FEs are distinguished from peripheral FEs. Although in FrameNet recursivity is not supposed to be a defining feature of frames, each so-called "frame definition" made available for each annotated frame comprises a set of attested frame-to-frame relations (cf. also Fillmore et al., 2003, pp. 304-313). Hence, frames are interconnected with one another, albeit in a much more restrictive way than in Barsalou's approach which hypothesizes that each frame element (attribute, value) is re- 
cursive in nature. Table 2 summarizes the most important commonalities and differences of both approaches to cognitive frames.

Table 2: Commonalities and differences of Barsalou's and FrameNet's approach to frames

\begin{tabular}{|c|c|c|}
\hline & Barsalou's approach to frames & FrameNet \\
\hline \multirow{3}{*}{$\begin{array}{l}\text { Theory- } \\
\text { oriented } \\
\text { aspects }\end{array}$} & $\begin{array}{l}\text { - cognitive theory of mental repre- } \\
\text { sentation }\end{array}$ & $\begin{array}{l}\text { - linguistic theory based on seman- } \\
\text { tic and syntactic valency }\end{array}$ \\
\hline & - focus on sortal nouns & - focus on verbs and deverbal nouns \\
\hline & $\begin{array}{l}\text { - compatible with concept type the- } \\
\text { ory }\end{array}$ & [unspecified and not integrable] \\
\hline Methodology & $\begin{array}{l}\text { - partly data-driven, partly introspec- } \\
\text { tion }\end{array}$ & $\begin{array}{l}\text { - data-driven, bottom-up investiga- } \\
\text { tions by rich semantic annotations }\end{array}$ \\
\hline \multirow[t]{3}{*}{$\begin{array}{l}\text { Frame } \\
\text { structure }\end{array}$} & $\begin{array}{l}\text { - distinction between attributes and } \\
\text { values }\end{array}$ & $\begin{array}{l}\text { - distinction of peripheral and core } \\
\text { frame elements }\end{array}$ \\
\hline & - recursivity & [unspecified but integrable] \\
\hline & [unspecified and impossible] & $\begin{array}{l}\text { - distinction between types of frame } \\
\text { relations }\end{array}$ \\
\hline \multirow{4}{*}{$\begin{array}{l}\text { Application of } \\
\text { frames in the } \\
\text { domain of AA }\end{array}$} & $\begin{array}{l}\text { - focus on relational and functional } \\
\text { nouns }\end{array}$ & - focus on deverbal nouns and verbs \\
\hline & [unspecified but integrable] & $\begin{array}{l}\text { - distinction between frame evoca- } \\
\text { tion and invocation }\end{array}$ \\
\hline & $\begin{array}{l}\text { - integration of relational/functional } \\
\text { concepts and theory of determina- } \\
\text { tion }\end{array}$ & - integration of relational concepts \\
\hline & - focus on nominal antecedents & - focus on verbal antecedents \\
\hline
\end{tabular}

What are the benefits of a FrameNet and a Barsalou-inspired approach to associative anaphora? In contrast to the latter, FrameNet allows for explaining anaphors with antecedents surfacing as verbs and deverbal nouns. Given the analysis above, investigations of associative anaphors provide insights into the composition of frames evoked by verbs and deverbal nouns on the text level, since associative anaphors specify FEs of the frame evoked by the anchor frame element. Subsequently, new FEs may be defined on the basis of annotated anaphors, and lexical entries provided by FrameNet may be supplemented accordingly. Note also that each associative anaphor establishes a specific semantic relation to its antecedent and thus offers linguistic evidence for frame-to-frame-relations. Composition and inheritance, as described by Fillmore \& Baker (2001), are ubiquitous 
relation types but besides the frame-to-frame relations identified by FrameNet many more seem to be relevant to resolve associative anaphors (cf. Kleiber, 2001; Greber, 1993). To this end, an interesting issue for future research would be whether attested relations are item-specific or rather stable across exemplars within a domain.

A fundamental caveat of a FrameNet approach to associative anaphors concerns the exclusion of sortal nouns as frame-evoking lexical units (Ruppenhofer et al., 2010, p. 5). In turn, Barsalou has developed his frame theory on the basis of sortal concept. However, he does not seem to be aware of the limitations involved in this approach; at least the reader is left wanting some reflections on the linguistic nature of the analyzed concepts. In Löbner (1998) and within the research projects SFB 991 and FOR 600, Barsalou's frame theory is supplemented by Löbner's concept type theory, yielding a substantial theoretical extension in that attributes are equated with functional nouns. Nonetheless the extended Barsalou approach still focuses on nominal concepts. A full-fledged frame theory of verb frames based on Barsalou's approach has not yet been developed.

Apart from sortal concepts also individual and relational concepts are integrated in Barsalou's frame theory, namely in such way that sortal, relational, and individual concepts may constitute frame attributes if they are shifted, or coerced, to functional concepts due to linguistic cues such as definitness markers (cf. Löbner, 2011). At this point, however, the empirical issue arises whether it is useful to principally restrict frame attributes to the set of functional concepts. IAAs, as exemplified in (2), prototypically surface as relational nouns (e.g., window), and due to the property of indefiniteness, they are not object of a conceptual shift. But, then, are there empirical reasons for the assumption that they do not figure as attributes in the frame evoked by the antecedent? In the case of DAAs, on the other hand, equating attributes with functional concepts helps to explain the cognitive mechanism underlying anaphora resolution: Since DAAs are interpreted as functional concepts in context, their possible referents are restricted to only one referent. In this respect, a FrameNet approach to DAA does not provide a suitable account of DAA resolution; at the same time, no principal problems arise in the domain of IAAs. A more comprehensive theory of AA based on Barsalou frames has to address the following research issues: To what extent and under which conditions do head nouns of DAAs call for type shifts in order to motivate a functional interpretation of the nouns in question? 


\section{References}

To conclude, FrameNet and Barsalou's approach complement each other in such a way that the latter concentrates on sortal concepts functioning as frameevoking elements, while FrameNet focuses on relational concepts, particularly verbs and deverbal nouns. Barsalou disregards semantic and syntactic valences of each frame-evoking word, whereas valency provides the very basis for the FrameNet methodology. This finding gives rise to issues of the following kind: How can FrameNet account for sortal nouns serving as associative anaphors? And how can, in turn, Barsalou's approach account for verbs serving as associative anaphors? What's the theoretical status of sortal nouns within FrameNet, and in what respect do verb frames differ from noun frames in Barsalou's approach? More generally, which linguistic elements evoke frames in each approach? It is beyond the scope of this article to provide answers to these questions. However, as I hope to have shown, there are several complementary research aspects of FrameNet and Barsalou's approach to frames and its extensions within FOR 600 and SFB 991. The diverging viewpoints and starting assumptions stimulate each other, pointing to a more comprehensive frame theory.

\section{Acknowledgment}

Many ideas introduced and discussed in this paper were developed in close cooperation with collaborators of the research unit "Functional Concepts and Frames" (FOR 600) and the SFB 991 "The Structure of Representations in Language, Cognition, and Science”, both funded by the German Research Foundation (DFG). In particular, I am indebted to the speaker of the research project, Sebastian Löbner, as well as Christian Horn and Nicolas Kimm.

\section{References}

Barsalou, L. W. 1992. Frames, concepts, and conceptual fields. In E. F. Kittay \& A. Lehrer (eds.), Frames, fields, and contrasts: New essays in semantic and lexical organization, 21-74. Hillsdale, NJ: Lawrence Erlbaum Associates.

Barsalou, L. W. 1993. Flexibility, structure, and linguistic vagary in concepts: Manifestations of a compositional system of perceptual symbols. In A. C. Collins, S. E. Gathercole \& M. A. Conway (eds.), Theories of memory, 29-101. London: Lawrence Erlbaum Associates. 
Barsalou, L. W. \& C. R. Hale 1993. Components of conceptual representation: From feature lists to recursive frames. In I. Van Mechelen, J. Hampton, R. Michalski $\&$ P. Theuns (eds.), Categories and concepts: Theoretical views and inductive data analysis, 97-144. San Diego, CA: Academic Press.

Boas, H. C. 2005. From Theory to Practice: Frame Semantics and the Design of FrameNet. In S. Langer \& D. Schnorbusch (eds.), Semantik im Lexikon, 129160. Tübingen: Narr.

Charniak, E. 1976. A framed painting: The representation of a common sense knowledge fragment. Cognitive Science 1. 355-394.

Clark, H. H. 1975. Bridging. In R.C. Schank \& B.L. Nash-Webber (eds.), Theoretical issues in natural language processing, 169-174. New York: Association for Computing Machinery.

Fillmore, C. J. 1976. The need for a frame semantics within linguistics. In H. Karlgren (ed.), Statistical Methods in Linguistics 12, 5-29.

Fillmore, C. J. 1977. Scenes-and-frames semantics. In A. Zampolli (ed.), Linguistic Structures Processing, 55-81. Amsterdam/New York/Oxford: North Holland.

Fillmore, C. J. 1985). Frames and the semantics of understanding. Quaderni di Semantica 6 (2). 222-254.

Fillmore, C. J. 2006). Frames Semantics. In K. Brown (ed.), Encyclopedia of Linguistics and Language, Vol. 4, 613-620. Amsterdam: Elsevier.

Fillmore, C. J., C. R. Johnson \& M. R. Petruck 2003. Background to FrameNet. International fournal of Lexicography 16 (3), 235-250.

Fillmore, C. J., M. R. Petruck, J. Ruppenhofer \& A. Wright 2003. FrameNet in Action: The Case of Attaching. International Journal of Lexicography 16 (3), 297332.

Fillmore, C. J. \& C. F. Baker 2010. A Frames Approach to Semantic Analysis. In B. Heine \& H. Narrog (eds.), The Oxford Handbook of Linguistic Analysis, 313339. Oxford: Oxford University Press.

Fillmore, C. J. \& C. F. Baker 2001. Frame Semantics for Text Understanding. Proceedings of WordNet and Other Lexical Resources Workshop. NAACL, Pittsburgh, June, 2001.

Fillmore, C. J., C. Wooters \& C. F. Baker 2001. Building a Large Lexical Databank Which Provides Deep Semantics. Proceedings of the Pacific Asian Conference on Language, Information and Computation. Hong Kong. 


\section{References}

Greber, E. 1993. Zur Neubestimmung von Kontiguitätsanaphern. Sprachwissenschaft 18 (4). 361-405.

Hawkins, J. A. 1978. Definiteness and Indefiniteness. A Study in Reference and Grammaticality Prediction. London: Croom Helm.

Hayes, P. J. 1980. The Logic of Frames. In D. Metzing (ed.), Frame Conceptions and Text Understanding, 451-458. Berlin/New York: de Gruyter.

Heim, I. 1982. The semantics of definite and indefinite noun phrases. Dissertation. Schriftenreihe des Sonderforschungsbereichs 99, Linguistik, Nr. 73. Konstanz: Universität Konstanz.

Horn, C. \& N. Kimm 2014. Concept types in German fictional texts. In T. Gamerschlag, D. Gerland, R. Osswald \& W. Petersen (eds.), Concept Types and Frames. Applications in Language and Philosophy, 343-362. Dordrecht, NL: Springer.

Kleiber, G. 2001. L'anaphore associative. Paris: Presses Universitaires de France.

Löbner, S. 1998. Definite associative anaphora. In S. Botley (ed.), Approaches to discourse anaphora: proceedings of DAARC96. Lancaster: Lancaster University. [Available at http://user.phil-fak.uni-duesseldorf.de/ loebner/publ/DAA -03.pdf]

Löbner, S. 2011. Concept types and determination. fournal of Semantics 28 (3), 279-333.

Lyons, C. 1999. Definiteness. Cambridge: Cambridge University Press.

Matthes, J. 2007. Framing-Effekte. Zum Einfluss der Politikberichterstattung auf die Einstellungen der Rezipienten. München: Verlag Reinhard Fischer.

Minsky, M. 1975. A framework for representing knowledge. In P. Winston (ed.), The Psychology of Computer Vision, 211-277. New York: McGraw-Hill.

Petersen, W. 2015. Representation of Concepts as Frames. In Gamerschlag T., D. Gerland, R. Osswald \& W. Petersen (eds.), Meaning, Frames, and Conceptual Representation, 39-63. Studies in Language and Cognition 2. Düsseldorf: Düsseldorf University Press. (Reprinted from J. Skilters, F. Toccafondi \& G. Stemberger (eds.), Complex Cognition and Qualitative Science. Volume 2 of The Baltic International Yearbook of Cognition, Logic and Communication, 151170, University of Latvia, Riga, 2007.)

Ruppenhofer, J., M. Ellsworth, M. R. Petruck, R. C. Johnson \& J. Scheffczyk 2010. FrameNet II: Extended Theory and Practice. September 14, 2010. [Available at: https://framenet2.icsi.berkeley.edu/docs/r1.5/book.pdf]. 
Schank, R. C. \& R. P. Abelson 1977. Scripts, Plans, Goals and Understanding. An Inquiry into Human Knowledge Systems. Hillsdale: Erlbaum.

Scheufele, B. 2003. Frames - Framing - Framing-Effekte. Theoretische und methodische Grundlegung sowie empirische Befunde zur Nachrichtenproduktion. Wiesbaden: Westdeutscher Verlag.

Schwarz, M. 2000. Indirekte Anaphern in Texten. Studien zur dömanengebundenen Referenz und Kohärenz im Deutschen. Tübingen: Niemeyer.

Schwarz, M. 1996. Lexikalische und konzeptuelle Restriktionen beim Verstehen direkter und indirekter Anaphern. In F. Hundsnurscher \& E. Weigand (eds.), Lexical Structures and Language Use, 399-407. Tübingen: Niemeyer.

Ziem, A. 2008. Frames und sprachliches Wissen. Kognitive Aspekte der semantischen Kompetenz. Berlin/New York: de Gruyter.

Ziem, A. 2012. Token-Konzepte, Type-Konzepte und das Prinzip der Rekursivität. In E. Fricke \& M. Voss (eds.), 68 Zeichen für Roland Posner. Ein semiotisches Mosaik / 68 Signs for Roland Posner. A Semiotic Mosaic, 69-79. Tübingen: Stauffenburg.

\section{Author}

Alexander Ziem

University of Düsseldorf

Faculty of Philosophy

ziem@phil.hhu.de 